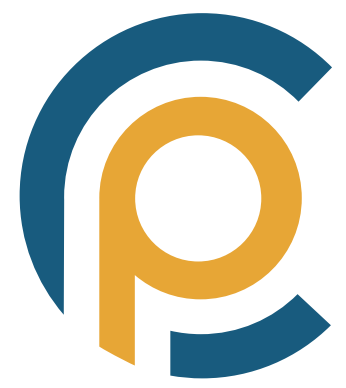

\title{
Crisis de Valores y Deshumanización: Una Reflexión Actual a Partir del Holocausto
}

\author{
Crisis of Values and Dehumanization: \\ A Current Reflection from the Holocaust
}

Recibido: 19/03/2020 | Revisado: 28/04/2020 | Aceptado: 31/05/2020 | Publicado: 30/06/2020

Resumen: Esta propuesta didáctica surge de la necesidad de abordar un fenómeno social de plena actualidad y de gran transcendencia: la llegada masiva de refugiados a Europa. Para ello, se parte del estudio de la persecución y aniquilación sistemática de los judíos por parte del Estado alemán y sus colaboradores durante el segundo tercio del siglo pasado. Desde él, se pueden desarrollar contenidos sociales que favorezcan la comprensión, análisis y reflexión de la realidad histórica y social del presente. El objetivo principal de este trabajo es que los alumnos conozcan en profundidad la ideología del nacionalsocialismo alemán, para servirles de reflexión a la crisis de valores en la que se encuentran actualmente las democracias europeas, y a la deshumanización que sufren miles de personas que huyen de su país para labrarse un porvenir mejor. Abordar un tema de estas características toma especial relevancia en un momento en el que hemos visto crecer actitudes y conductas racistas y discriminatorias en nuestra sociedad; que se ven agudizadas por la entrada de partidos ultras en los parlamentos nacionales y en las instituciones europeas, poniendo en jaque los valores de tolerancia y respeto que deberían caracterizar toda sociedad democrática. Ante tal escenario, educar en y para la ciudadanía se vuelve una tarea fundamental en las aulas.

Palabras clave: sistema de valores, derechos humanos, pensamiento convergente-divergente, creatividad, cooperación, debate, toma de decisión, percepción del otro.
Abstract: This educational proposal emerges from the need of approaching a current and significant social phenomenon: the massive arrival of refugees in Europe. For this purpose, the origin of this study goes back to the pursuit and annihilation of the Jews by the German state and their partners during the second third of the last century. From that perspective, a lot of social contents can be developed so that it helps to the understanding, analysis and reflection of today's historical and social reality. The target of this project focuses on making the students aware of the German national-socialism so they can ponder the current crisis of values of the European democracies as well as the dehumanization that thousands of people who run away from their origin countries are suffering today. Approaching an issue like this is significant due to the racist and discriminatory attitudes that have been emerging in the past few years, aggravated by ultra-political parties in national parliaments and European institutions. These behaviours are challenging the tolerance and respect values that should be characteristic in a democratic society. In such a situation, educating in and to the citizenship becomes something vitally important.

Keywords: value system, human rights, convergent-divergent thinking, creativity, cooperation, debate, decision making, perception of others. 
Es innegable que nuestra sociedad se encuentra inmersa en un proceso de globalización que condiciona en gran medida los métodos de enseñanza y aprendizaje. La globalización, entendida como la mayor contracción del tiempo y del espacio jamás vista, da a los medios de comunicación un papel protagonista en la educación de los jóvenes. La expansión de las nuevas tecnologías de la información y la comunicación han hecho, que actualmente, contemos con un volumen de información tan elevado que nuestro alumnado se sitúe ante un sinfín de contextos sociales que, a menudo, distorsionan la realidad en la que viven.

Medios como la televisión o Internet ejercen tal influencia que han modificado la forma en cómo nos relacionamos y aprendemos. A través de estos medios, escenas de guerra, violencia, intolerancia y discriminación han pasado a ser un elemento habitual y cotidiano en nuestras vidas. Además, el consumo desmesurado de información conduce, en la mayoría de las ocasiones, a una frivolización de los sucesos y a una falta de reflexión y crítica por parte del consumidor. Este hecho, denominado por García y De Alba (2008) como «cultura de superficialidad», y sumado a un modelo educativo caduco falto de espacios de debate, reflexión y crítica, dificulta que el alumnado pueda adquirir las competencias básicas necesarias para la vida adulta.

La presente propuesta didáctica parte del estudio de la ideología nacionalsocialista y el holocausto con el fin de abordar un fenómeno social de plena actualidad y de gran transcendencia histórica como es la llegada de refugiados a Europa. Somos de la opinión que desde la enseñanza del Holocausto, y por el propio carácter vertebrador de la historia, se pueden desarrollar contenidos sociales que favorezcan la comprensión, análisis y reflexión de la realidad histórica y social del presente. Nuestro objetivo principal es que el alumnado de último curso de educación secundaria conozca mediante esta unidad el proceso de cosificación del individuo que realizó el Estado alemán y sus colaboradores para servirles, así, de reflexión a la crisis de valores en la que se encuentran las democracias europeas ante la gestión de este fenómeno, así como a la deshumanización que sufren miles de personas que huyen de su país para labrarse un porvenir mejor.

\section{Desarrollo}

\section{Tema y Presentación de la Unidad}

La unidad didáctica que presentamos está diseñada para $4^{\circ}$ curso de la Enseñanza Secundaria Obligatoria en la materia de Ciencias Sociales, Geografía e Historia y tiene como finalidad principal abordar la crisis de valores y el proceso de deshumanización del individuo que realizó el Estado nacionalsocialista alemán y sus consecuencias, Su estudio pretende servir de reflexión a nuestro alumnado sobre la problemática social en cuanto a la gestión de la llegada de miles de refugiados en el continente europeo, siempre con una debida contextualización que merece.

Si bien es cierto que los contenidos de esta unidad pueden desarrollarse desde otras materias como Cultura y Valores Éticos, al tratar cuestiones estrechamente relacionadas con los valores ético-morales de igualdad, respeto, tolerancia y dignidad de las personas; las Ciencias Sociales y, en concreto, la historia es una de las materias que ofrece mayores posibilidades en la formación e instrucción de los jóvenes, al constituir una poderosa herramienta al servicio de la emancipación individual y social de la población. Además, su alto valor formativo favorece la comprensión del presente a partir de los problemas de las sociedades pasadas, contribuyendo a desarrollar facultades intelectuales, enriqueciendo otros temas del currículum, estimulando aficiones para el tiempo libre y ayudando a adquirir sensibilidad social (Prats y Santacana, 2011).

Por lo tanto, el estudio de la Historia, y más concretamente de la Historia Contemporánea, tiene como función principal contribuir a formar ciudadanos críticos y democráticos (Hernández, 2002) y capacitarlos "para intervenir, participar y convivir como ciudadanos en un mundo que se nos presenta con una gran diversidad y pluralidad" (Ortuño, Gómez y Ortiz, 2012, p. 65). Educar en el respeto, la colaboración 
y el compromiso supone poner las bases para la construcción de una sociedad más libre, equitativa y justa (Casas, 2003). Con esta voluntad, la escuela ha de ofrecer espacios para que el alumnado cultive un pensamiento crítico y desarrolle los valores cívicos, así como ensayar metodologías de trabajo activas y participativas en donde el alumno sea el principal y verdadero protagonista de su aprendizaje.

\section{Objetivos Didácticos}

Dicha unidad se desarrolla en cinco sesiones lectivas de cincuenta minutos cada una y pretende que el alumnado logre los siguientes objetivos didácticos:

1. Comprender, analizar y relacionar la crisis del período de entreguerras con la aparición de los totalitarismos y, por tanto, valorar el fenómeno específico dentro de su contexto histórico.

2. Elaborar un juicio crítico en torno a los movimientos totalitarios, la represión y la deshumanización del individuo.

3. Fomentar la tolerancia y el respeto hacia otras culturas y religiones, y valorar la igualdad de todas las personas independientemente de su edad, sexo, religión, procedencia, orientación sexual o de cualquier otra índole.

4. Utilizar fuentes primarias como herramientas para estudiar conceptos históricos básicos y hacer un buen uso del vocabulario histórico.

5. Diferenciar y hacer un buen uso de los términos de inmigrante y refugiado, así como comprender las causas por las que una persona abandona su país de origen.

6. Sensibilizar al alumnado de que la guerra o los genocidios no son la solución de nada, rechazar las actitudes que conducen a ello y valorar el diálogo para la resolución de conflictos.

7. Dar oportunidad a los alumnos para que expresen su opinión acerca de lo acontecido y los problemas político-sociales actuales con la debida seriedad.

8. Adquirir herramientas intelectuales que les permitan avanzar en su proceso de aprendizaje y fomenten su propia autonomía.

\section{Contexto de la Experiencia y sus Destinatarios}

Este trabajo nace ante la creciente presencia de actitudes y conductas racistas, xenófobas y discriminatorias para nuestra sociedad, que se traducen, en algunos casos, en la entrada de partidos políticos de corte neofascista, racista, antiinmigrantes, islamófobos, antieuropeístas o simplemente violentos en los parlamentos nacionales y en las instituciones europeas. Mediante el uso de discursos populistas, basados en un sentimiento nacionalista acérrimo y en la necesidad de defender y proteger los respectivos territorios frente a «amenazas» internas y externas, ponen en jaque los valores de tolerancia y respeto que deberían regir todas las sociedades democráticas. Asimismo, la multiculturalidad, cada vez mayor en nuestras aulas, nos lleva a realizar un ejercicio que sirva al alumnado de reflexión y prevención ante actitudes y situaciones discriminatorias y racistas contra aquello que se concibe como desconocido o diferente.

Si bien esta unidad está pensada para desarrollarse en el último curso de secundaria, también es cierto que curricularmente puede trabajarse en $1^{\circ}$ curso de bachillerato en el itinerario de humanidades en la materia de Historia del Mundo Contemporáneo. A pesar de esta posibilidad, creemos más apropiado que se lleve a cabo en la etapa obligatoria del escolar con el fin de ofrecer a todo nuestro alumnado, más allá de si continúa sus estudios y de sus preferencias académicas, un espacio de debate y reflexión en torno a cuestiones sociales actuales. En cualquiera de los casos, educar en y para la ciudadanía se vuelve una tarea fundamental en las aulas.

\section{Desarrollo de los Contenidos}

En relación al desarrollo de los contenidos que trabajaremos a lo largo de la unidad, éstos deberán replantearse según el tipo de alumnado y la realidad del centro en la que nos encontremos; ampliándolos o modificándolos en función de nuestros intereses, necesidades u objetivos. Con la clara 
voluntad de contribuir a formar ciudadanos críticos y reflexivos, coincidimos con Ruiz Varona (2002, p. 109) en que los contenidos conceptuales y procedimentales «deben estar subordinados en un discurso en torno a los valores y actitudes con una intención emancipadora y transformadora, y con un planteamiento beligerante; $y$, por tanto, con las características de una sociedad profundamente injusta y desigual». La nazificación de la sociedad alemana y el Holocausto serán abordados desde la perspectiva de valores y la deshumanización del individuo. Trataremos de que el alumnado comprenda los pilares ideológicos en los que se sustenta el nazismo y que dieron legitimidad a la persecución y aniquilación de aquellos sujetos cuya existencia suponía un estorbo para la construcción de una sociedad racialmente pura.

Para ello, se nos hace especialmente complicado abordar su estudio sin trabajar previamente los conceptos de raza, antisemitismo o desigualdad. En una primera sesión, partiremos de preguntas verbales que hagan reflexionar al alumnado acerca de si elegimos el color de nuestra piel, si existen las razas o si elegimos el lugar de nacimiento. El objetivo es tratar de dar con una definición lo más ajustada posible de estos términos, e iniciar un debate en torno a si tiene sentido ser racistas o xenófobos en una sociedad plural en donde nadie elige el lugar, el color o el sexo con el que se nace. A continuación, introduciremos el concepto de antisemitismo entendido como la manifestación hostil hacia el colectivo judío. No nos detendremos demasiado en él, puesto que se pretende recuperar y trabajar con mayor profundidad en la siguiente sesión.

Posteriormente, se presenta a los alumnos un fragmento del Discurso sobre el origen y los fundamentos de la desigualdad entre los hombres (1755) de Rousseau en donde se habla de la existencia de desigualdades naturales o físicas, y de desigualdades morales o políticas. Se les pide que elaboren, por grupos, un listado de las desigualdades de las que hace referencia el texto, digan qué otras formas de desigualdad conocen, y qué relación establecen con el racismo. La idea principal que queremos transmitirles es que todos los individuos son diferentes entre sí, y que existe una lucha milenaria por la respectiva supervivencia; pero que, por primera vez en la historia, contamos con una experiencia cuya intención era construir una sociedad en base a la desigualdad. La elección del pensamiento de Jean-Jacques Rousseau no es aleatoria, pues aparte de considerar su obra idónea para trabajar el concepto de desigualdad y sus distintas modalidades, nos permite incidir en el intento de los nazis en encontrar una explicación racional al desastre en el que se encontraba Alemania.

Los regímenes parlamentarios surgidos en Europa tras la Primera Guerra Mundial, vieron como la sociedad iba perdiendo la confianza y dejaba de prestar apoyo a los principios creadores del mundo contemporáneo establecidos por la llustración, y permitiendo el paso a dictaduras. Las decisiones que se toman en Versalles no hacen más que agravar los serios problemas socioeconómicos que atravesaba el país. Es en este caldo de cultivo de insatisfacción, humillación y desesperación que el partido nazi aparece como el único capaz de restablecer el orden. Su líder, Adolf Hitler, un hombre carismático cuyos discursos estaban impregnados de ideas racistas, antidemocráticas y anticomunistas, culpabilizaba a marxistas y judíos de los males que padecía Alemania, y advertía de la degeneración que padecía la sociedad en términos biológicos. Analizar fragmentos del Mein Kampf (1925) en el aula, nos permite ahondar en el sentimiento europeo de decadencia y la crisis de valores que atravesaba Europa y que, en el caso alemán, pasaba por el gran mito de la degeneración biológica, la enfermedad y la pérdida de vigor de la civilización.

En una segunda sesión, continuaremos profundizando en el concepto de degeneración biológica. Consideramos que este es un aspecto fundamental para que el alumnado comprenda como una sociedad moderna y socialmente avanzada como la alemana, que alcanza un desarrollo técnico y médico sin precedentes, llega a la convicción de que hay vidas que no tienen valor para ser vividas. Debe hacerse hincapié también que el fascismo no es únicamente represión, violencia, intimidación y expulsión sino también un proyecto de inclusión que gozó de gran aceptación popular y que reforzó el sentimiento de identidad. La destrucción de las instituciones de Weimar fue posible, en parte, porque millones de alemanes asumieron que el racismo dotaba de un contenido científico a las desigualdades biológicas de los individuos. 
El fascismo es un movimiento o fenómeno social que tiene como objetivo restablecer el orden natural y tradicional mediante la creación de una nueva sociedad contraria a los valores del liberalismo. Se trata de una propuesta utópica en la que muchos se sintieron identificados y que no debe ser vista como una anormalidad de su época, sino todo lo contrario. El nacionalsocialismo concluyó que para poner fin a esta degeneración se debían eliminar todos aquellos elementos que se consideraban impuros o peligrosos. Los nazis tenían una absoluta obsesión por todas aquellas enfermedades que provocaban la pérdida de la calidad humana y embrutecía la pureza de la sangre. Si bien por un lado, la sangre es el elemento más personal que uno tiene, por el otro también representa al conjunto de la raza. Los avances científicos no sólo permitieron detectar aquellas personas incurables sino también aquellas personas sanas que podían dar lugar a una descendencia inservible en términos de eficiencia productiva.

Llegados a este punto, conviene situar a los alumnos ante el hecho de que los primeros que mueren en cámaras de gas no son judíos sino personas con enfermedades incurables, inadaptados o con algún tipo de malformación. Aportar fotografías del cementerio de Hadamar, de Viktor Brack o del documento en donde Hitler autoriza el programa de eutanasia AktionT4, puede servir para este propósito. La eutanasia de enfermos e inválidos, presentados como actos de compasión, sirvieron de prueba a las atrocidades que años más tarde perpetuaron contra la comunidad judía. Recurrir a imágenes de tribunales médicos puede ser una muy buena fórmula para abordar la complicidad de la comunidad médica ante unas prácticas en beneficio del progreso. Lo que el nazismo planteaba era una lectura interesada de la biología y la antropología que condujo al exterminio sistemático del pueblo judío. Más de siete millones de judíos fueron víctimas de la persecución y el asesinato burocráticamente organizado por el Estado alemán y sus colaboradores.

Proseguiremos nuestra unidad en una tercera sesión con el análisis de algunos relatos e imágenes relativos a la experimentación con prisioneros judíos. Testimonios escritos de médicos, el retrato de Josef Mengele o imágenes de niños judíos en los laboratorios, pueden ser útiles para abordar estas cuestiones. A nuestro parecer, resulta especialmente interesante el testimonio del doctor Miklós Nyiszli en donde nos relata los experimentos a los que eran sometidos los gemelos para hallar la fórmula que permitiese la multiplicación de la raza aria. Esta obsesión, nos permite trabajar con nuestros alumnos el gran prestigio social que suponía contribuir a la comunidad con una descendencia sana, así como el incremento de nacimientos en Alemania durante los años 30. Todas estas prácticas deben entenderse como una terapia de carácter racial para restablecer la salud nacional que pasa, inevitablemente, por un proceso de deshumanización de los sujetos considerados indignos e impuros.

Cuando nos centremos en el colectivo judío, es conveniente recordar a nuestros alumnos que el antisemitismo no es un hecho exclusivamente alemán, sino que también lo encontramos en otros países europeos, coincidiendo con el apogeo de las ideas nacionalistas y el expansionismo colonial iniciado a finales del siglo XIX. Las principales potencias europeas del momento recurrieron a una supuesta superioridad racial para legitimar las actuaciones que se estaban llevando a cabo en las colonias. La difusión de la cultura, la religión y la civilización europea era, en palabras del escritor británico Rudyard Kipling (1865-1936), la responsabilidad del hombre blanco. Esta cuestión puede reforzarse, siempre que se considere oportuno, aportando algunas de estas posturas para ver qué similitudes presenta con el discurso nacionalsocialista.

Para comprender la complejidad de este fenómeno, es preciso que los alumnos entiendan que no se trata de un hecho planeado sino que es fruto de un proceso gradual que se inicia con la privación de derechos y posesiones a los judíos, pasa por la concentración en guetos, y concluye con el traslado a campos de concentración diseminados por Alemania y Polonia donde son obligados a trabajos forzados hasta la extenuación. Si bien contamos con un sinfín de recursos a nuestra disposición para trabajar la confiscación de bienes y la guetización, en nuestra unidad nos centraremos básicamente en los campos de concentración. Nuestro interés reside, principalmente, en que el alumno conozca qué diferencias hay entre un sistema concentracionario y un sistema meramente penitenciario. 
Para ello, tomaremos el caso de Dachau al ser, a nuestro parecer, el más representativo. Su estudio nos permite ver cómo se pasa de un sistema penitenciario con supervisión judicial, a un sistema concentracionario exento de todo control y en donde se llevan a cabo prácticas moralmente reprobables cuya finalidad era generar un sentimiento de impotencia e inseguridad continua entre sus presos. Este funcionamiento basado en la sistematización del terror y la arbitrariedad del sistema, es donde reside la fortaleza del nacionalsocialismo. Además, el hecho de que Dachau fuese ideado como un centro de internamiento de opositores políticos, refuerza la idea de que el Holocausto no estuvo planeado en sus orígenes, tal y como ya habíamos podido comprobar con las primeras víctimas de las cámaras de gas. Asimismo se pretende trabajar sobre la idea de que los campos de concentración no son un producto de la guerra sino que éstos fueron ideados y llevados a cabo antes del conflicto bélico.

En una cuarta sesión, nos centraremos en los refugiados que entre 1933 y 1939 huyeron de Alemania y Austria en busca de asilo. Ante la llegada masiva de refugiados, los países receptores empezaron a poner restricciones y a negar la entrada de miles de personas alegando no tener la capacidad para acogerlos a todos. A pesar de los obstáculos burocráticos, y después de diversas tentativas, algunos judíos pudieron entrar de forma ilegal. Para trabajar todos estos aspectos se recurre al visionado de Segmentos para la clase: la experiencia migratoria. Un recurso educativo a disposición de los educadores en donde siete supervivientes nos relatan su experiencia de emigrar de Europa y de reconstruir sus vidas en distintos países de América Latina.

En un segundo bloque, abordaremos específicamente la cuestión de los refugiados en el siglo XXI. El objetivo principal es que el alumnado tome conciencia y debata en torno a las formas de desigualdad y discriminación que se dan en la actualidad. Para empezar es preciso que se conozcan las diferencias que hay entre un refugiado y un inmigrante. Para ello recurriremos a la lectura del Estatuto del Refugiado de la ONU de 1951. Según el Comisionado de Naciones Unidas para Refugiados, se entiende que un refugiado es aquella persona que huye de un país en conflicto o existen fundados temores de ser perseguida por motivos de raza, religión, nacionalidad, pertenencia a un determinado grupo social u opiniones políticas y, por lo tanto, tiene derecho a pedir asilo político. Un inmigrante, en cambio, es aquel migrante que abandona su país de origen por decisión propia o conveniencia personal, generalmente por motivos económicos.

Como actividad final, en la última sesión, se propone una experiencia de gamificación en el aula. Contra viento y marea es un juego online en donde el alumnado debe ponerse en la piel de un refugiado que huye de su país. Se trata de una iniciativa didáctica de la ACNUR (o UNHCR en inglés) que pone en valor la dignidad de las personas y el respeto a los Derechos Humanos. A nuestro parecer, resulta muy instructivo para una educación en valores y permite hacerse una idea de cuáles son los obstáculos que debe salvar miles de personas que huyen de sus países. La historia se divide en tres momentos: en el primero, se establecen las condiciones de vida y se prepara la huida del país; en el segundo, se produce propiamente el viaje de huida; y, en un tercero, la llegada al país de acogida. El juego se caracteriza por una toma de decisiones constante en donde el alumno asume la responsabilidad de sus actos. Qué decir y cómo actuar en un país sin libertades, qué ruta tomar para abandonar el país sin ser apresado, qué compañeros de viaje dejar atrás para continuar, o qué hacer para localizar ayuda cuando llega a su destino, son algunos de los dilemas que el juego plantea. Además, en la misma página web se ofrece una guia para el profesorado con un gran número de enlaces y recursos didácticos para trabajar con nuestro alumnado.

\section{Metodología}

En cuanto a la metodología de clase destacaremos la técnica de los seis sombreros la cual consiste en abordar y descomponer un problema desde sus múltiples enfoques (De Bono, 1988). Cada una de estas perspectivas está representada por un color e implica un tipo de pensamiento en función de las tareas, demandas o necesidades correspondientes de acuerdo a los objetivos propuestos (Herrandis, 2003). De este modo, el sombrero blanco se centra en los hechos y toma un carácter meramente objetivo; el sombrero rojo expresa las emociones y sentimientos; el negro ofrece la visión negativa de las 
cosas; el amarillo se encarga de hacer juicios positivos; el verde proporciona alternativas y soluciones creativas; $y$, finalmente, el sombrero negro alude al pensamiento ejecutivo y se ciñe al propio proceso de pensar.

El empleo de esta técnica tiene como objetivo propiciar el desarrollo del pensamiento lateral de los alumnos mediante discusiones grupales e intergrupales en torno a las distintas vías de aproximación a un mismo problema. Para De Bono (1988) el desarrollo del pensamiento lateral es posible cuando el alumno se ve obligado a representar el papel definido, dirigir la atención a diferentes aspectos del asunto, cambiar de manera conveniente el modo de pensar y aprender en base a unas reglas del juego. La educación secundaria es una etapa escolar idónea para promover espacios de debate, reflexión y crítica orientados a desarrollar la competencia social y ciudadana básica para la vida adulta, por lo que la metodología empleada debe invitar al diálogo, la participación y la interacción entre alumno y profesor. Además de fomentar el pensamiento crítico, esta técnica también ayuda a la cohesión del grupo y permite desarrollar valores propios de las sociedades democráticas como es la escucha activa y el respeto a las distintas opiniones.

Para poder llevarla a cabo correctamente en el aula es preciso que se hayan dedicado algunas sesiones previas para que el alumnado pueda familiarizarse con esta dinámica. Si bien es cierto que resulta ser una técnica muy eficaz ante temas controvertidos en donde las distintas posturas defendidas son irreconciliables, su autor nos advierte que si no se conduce adecuadamente puede generar conflictos que entorpezcan el proceso de aprendizaje. Por ello, el tiempo de ejecución no debe ser muy prolongado y los alumnos deben conocer de antemano cuál es su funcionamiento. Antes de pasar a abordar temas específicos del currículo, es aconsejable practicar con aspectos de índole más cotidiana que no requieran un conocimiento demasiado exhaustivo de la materia, puesto que el objetivo que se persigue no es tanto el producto final sino dar la oportunidad a pensar y actuar de acuerdo al estilo de pensamiento correspondiente.

En cualquier caso, el desarrollo pasa por tres fases. La primera consiste en plantear el problema o desafío a los distintos grupos de forma clara, precisa y sin hacer juicios de ningún tipo. También deberá ponerse especial atención en la organización de los grupos de discusión con el fin de buscar una cierto equilibrio y evitar agravios comparativos. Para que la técnica surta mayor efecto se recomienda que en un mismo grupo ningún miembro repita color de sombrero, puesto que de esta manera, y como sucede en el sistema de expertos, evitamos que se convierta en un grupo de trabajo convencional en donde unos hacen y otros observan. La discusión entre el grupo y el desarrollo de un cuerpo de argumentos se produce en una segunda fase. En ella, el alumno piensa de manera enfocada al color de pensamiento y se ve obligado a tomar constantemente decisiones para distinguir aquello relevante para su sombrero.

Finalmente, en una tercera y última fase, el debate se traslada a nivel de aula y los distintos grupos comparten las perspectivas y conclusiones a las que han llegado. El objetivo es ofrecer soluciones a partir de un análisis crítico de las distintas propuestas o tesis defendidas. El debate debe ser llevado casi en exclusividad por los mismos alumnos y el papel del profesor se restringe al de mero moderador. Únicamente intervendrá para reconducir el debate y así cumplir los objetivos didácticos fijados. En esta última fase es sobre todo donde deberá ponerse especial atención para evitar que la discusión genere tanta tensión como para desembocar en un conflicto, tal y como mencionábamos con anterioridad.

\section{Productos y Materiales}

Los materiales y recursos didácticos empleados han de ser coherentes al currículo, acordes a los objetivos programados, adaptados al nivel de desarrollo y madurez del alumnado, y han de potenciar la motivación por el estudio y el aprendizaje. Se considera imprescindible el libro de texto escolar, las fotocopias de los textos y fotografías utilizadas, las fichas de actividades extraídas de fuentes diferentes y variadas, las rúbricas con los criterios de corrección y las fichas de seguimiento para la evaluación continua. También es preciso bolígrafos, el cuaderno o libreta en donde el alumno suele tomar los 
apuntes y folios en blanco para utilizarlos durante las discusiones grupales. Contar con algún distintivo visual puede ayudar a que el alumno se meta más en el papel que ha de representar según el color de pensamiento asignado.

Los documentos, imágenes o vídeos utilizados deben introducirse de forma gradual con el fin de favorecer un buen proceso de aprendizaje. El lenguaje, por su lado, debe ser en todo momento comprensible por el alumnado, o en su defecto, poner a su disposición los medios para conocer el significado de las palabras o conceptos que desconozcan. De igual modo, es preferible calidad antes que cantidad $\mathrm{y}$, debe prestarse atención a la carga de trabajo que supone cada actividad. En la medida en que sea posible es conveniente proyectar los documentos en el aula, en especial para captar los detalles en las fotografías. En la última sesión es necesario, además, el uso de ordenadores o de algún dispositivo electrónico con conexión a Internet que permita simular su experiencia como refugiado. Como hemos indiciado con anterioridad, el producto principal que valoraremos será el portfolio de metacognición de cada alumno, en donde queden reflejados los conocimientos previos que tenía sobre el tema, describa cuál ha sido su proceso de aprendizaje, y exponga las reflexiones y conclusiones a las que llega.

\section{Evaluación e Instrumentos}

Si bien es cierto que existen varias definiciones al concepto de evaluación, la acepción más clásica la encontramos en Tenbrink (1981) que la define como el proceso por el cual obtenemos información, emitimos un juicio y tomamos decisiones en base a ello. El objetivo principal de la evaluación, por tanto, es verificar el cumplimiento de los objetivos, medir el grado de profundización del contenido mediante un sistema de calificación y hacer una valoración global del proceso de enseñanza-aprendizaje. Para realizar un seguimiento correcto de este proceso, la evaluación debe realizarse en tres momentos distintos: al inicio, durante y al final del proceso. En este sentido, la evaluación inicial permite hacernos con una idea general de cuáles son los conocimientos previos que tiene el alumnado, a la vez que permite introducirle en algunos conceptos que se trabajaran a lo largo de la unidad. La evaluación formativa o de seguimiento se centra en el propio proceso y se basa en obtener información del aprendizaje de los alumnos de forma regular. Por último, la evaluación sumativa consiste en valorar el resultado final y permite al alumno comparar el grado de conocimientos que tenía en el inicio y el final de dicho proceso.

Aunque en la legislación educativa se resalta la evaluación como un elemento de gran importancia en el currículo en donde distintos agentes intervienen en el proceso educativo, parece ser que los sistemas de evaluación actuales no corresponden al modelo educativo que se espera en el siglo XXI. La evaluación mediante un examen, en sus múltiples formas (tipo test, de desarrollo, oral, etc.), continúa siendo hoy en día el instrumento hegemónico en las aulas por la alta sensación de seguridad que genera para ambas partes. Por un lado, si bien existe consenso entre profesores sobre la necesidad de utilizar una amplia gama de instrumentos a la hora de evaluar, la mayoría continúa recurriendo al examen al considerarlo un instrumento objetivo, necesario e imprescindible, así como la única fórmula que garantiza un estudio regular en el alumnado (Alfageme, Miralles y Monteagudo, 2015). Para estos últimos, en cambio, el examen es visto como el principal elemento de su evaluación frente a otras formas como son trabajos, seminarios o proyectos; por lo que plantear formas de evaluación distintas a ésta resulta a veces algo polémicas y aumenta la incertidumbre del alumnado sobre lo que se espera de él (Molina, Miralles y Trigueros, 2014).

Parece ser que el problema de todo ello radica, tal y como apuntan las últimas publicaciones en la materia, en que la realización de exámenes no les permite adquirir las competencias básicas. Una investigación realizada por Monteagudo, Molina, Miralles y Belmonte (2010) apuntó que la adquisición y el desarrollo de competencias estaba especialmente ligada a la práctica y a la enseñanza de procedimientos, hecho que entraba en contradicción con el peso que verdaderamente tenían en las programaciones didácticas y en las pruebas donde los contenidos conceptuales eran claramente más abundantes. Llegados aquí, resulta interesante plantear una evaluación que se aleje de la repetición de los contenidos en su mayoría conceptuales y memorísticos que aparecen en los libros de texto, para 
formar en la adquisición de estas competencias en donde el alumno es protagonista activo de su propio aprendizaje (Miralles, Gómez y Monteagudo, 2012). Para ello, es conveniente propiciar situaciones de debate, reflexión e intercambio de ideas y puntos de vista en torno a fenómenos pasados y que forman parte de su día a día; y que éstas, posteriormente, sean tenidas en cuenta como partes neurálgicas en la evaluación. Para la corrección de las distintas tareas se precisa, por tanto, de un instrumento que permita realizar una valoración objetiva, precisa e imparcial del contenido adquirido, del grado de profundidad de los mismos, del esfuerzo y la constancia del alumno, y de la concepción que éste tiene sobre su propio aprendizaje.

El uso de la rúbrica aparece como la fórmula más adecuada para garantizar la ecuanimidad en el proceso de corrección y permite hacer un seguimiento del trabajo diario de nuestro alumnado, más aún cuando la experiencia docente demuestra que a partir de un número determinado de alumnos la evaluación continua se hace especialmente complicada, y ésta normalmente suele traducirse en controles regulares en forma de examen cuya finalidad es medir los conocimientos acumulados hasta el momento (Zaragoza, 2004). Además, la rúbrica también concede al alumno la posibilidad de valorar su producto y el de sus compañeros de acuerdo con unos criterios previamente fijados. Normalmente son los profesores los encargados en exclusiva de evaluar los aprendizajes, y la autoevaluación del alumnado raramente es tenida en cuenta para la evaluación, pues toma un carácter meramente informativo del estado en el que se encuentran (Sanmartí, 2007).

En el diseño de la rúbrica se deben recoger desde aspectos más procedimentales como son la búsqueda de información, su tratamiento y elaboración; hasta aspectos más actitudinales como es el intercambio de información entre compañeros, la calidad de las aportaciones, la existencia de un razonamiento crítico ante posturas propias y ajenas, el respeto a los turnos de palabra, la utilización de un vocabulario preciso, el grado de generosidad a la hora de permitir la participación de todos o, en este caso también, la seriedad a la hora de representar el modo de pensamiento asignado. La evaluación y calificación final será resultado de distintos componentes, cada uno de igual importancia para una correcta evaluación del proceso de aprendizaje. Por un lado, del promedio de calificaciones obtenidas en la valoración hecha del trabajo diario tanto individual como grupal. Por otro, de la realización de un portafolio de metacognición individual y la consiguiente autoevaluación que el alumno haga de sí mismo. Y, finalmente, de la valoración que puedan hacer los distintos grupos del trabajo de sus compañeros a partir de una rúbrica específica.

Todas y cada una de las tareas deberán ponerse en conocimiento del alumnado desde el primer día. El hecho de que el alumno conozca de antemano el modo y los aspectos que serán tenidos en cuenta para la evaluación influye de manera muy significativa en su aprendizaje (Merchán, 2007). Estudios en este sentido establecen que existe una correlación positiva entre el rendimiento académico y el conocimiento de los criterios de evaluación por parte del alumnado (Molina, Miralles y Trigueros, 2014), optimizando de los recursos cognitivos empleados para la resolución satisfactoria de la tarea y, por extensión, favorece el desarrollo y la consolidación de estrategias de aprendizaje (González y Tourón, 1992; Bernardo, 1995; Vallés, 1998).

En nuestra opinión, poner el acento en el proceso de aprendizaje del alumno, y no tanto en su resultado final, supone ver la evaluación como un elemento más en el proceso constructivista y abre la puerta a ensayar, desde la práctica docente, nuevas fórmulas de evaluación más ajustadas a las demandas y cambios de la sociedad actual. Abandonar la idea de evaluación como una mera traducción numérica, tal y como apuntan Monteagudo y Villa (2011), supone entender la evaluación como un instrumento más en el proceso de construcción de conocimientos y significados por parte del alumnado. Asimismo, reconsiderar la evaluación optando por aquellas fórmulas más procedimentales y actitudinales en donde el alumnado participa activamente en ella, contribuye a formar ciudadanos autónomos, libres, responsables y comprometidos con la propia tarea educativa. 
Es innegable que el Holocausto constituye uno de los temas de estudio más prolíferos y que mayor interés despierta entre el alumnado. A nuestro parecer, se trata de una herramienta de trabajo en el aula óptima para reflexionar acerca de las problemáticas sociales actuales, así como para despertar una sensibilización entre nuestro alumnado contra las injusticias cometidas en nuestra cotidianeidad. Este hecho cobra verdadera importancia en un momento en el que hemos visto incrementarse en los medios de comunicación las declaraciones y actitudes discriminatorias. Si bien éstos son un poderoso instrumento al servicio de la instrucción de los jóvenes, también contribuyen a mantener viva una lacra que hace tambalear una convivencia intercultural que pasa por el respeto y la tolerancia de las distintas opiniones y modos de vida. La educación para la igualdad y la dignidad de la persona humana requiere un ejercicio de responsabilidad y solidaridad por parte de todos, y nos ayuda a superar unos prejuicios que no tienen cabida en una sociedad plural e igualitaria. Únicamente mediante el pensamiento histórico podremos hacer frente a los desafíos que nos presenta la sociedad actual.

En nuestra opinión, y como ya hemos mencionado con anterioridad, el Holocausto constituye un tema de estudio que puede ser abordado de forma interdisciplinar desde distintas áreas y en sus dos vertientes. Por un lado, desde el área de lengua, filosofía, música, educación física, biología, etc. se pueden trabajar contenidos que favorezcan la comprensión del nazismo. La preocupación de los nazis por vigor físico y el deporte, o la historia del swing y el jazz pueden ser algunas propuestas para Educación Física y Música, respectivamente. Por el otro, se puede trabajar la cuestión de los refugiados. De cómo figuras, de los más variados campos y nacionalidades, fueron en su momento refugiados al tener de huir de sus países de origen: el físico Albert Einstein, el músico Pau Casals, el pintor Pablo Picasso, el cineasta Luis Buñuel, la escritora Isabel Allende, el bailarín Mikhaïl Baríxnikov o la activista Rigoberta Menchú, tan solo son algunos casos. Un estudio desde múltiples perspectivas puede ser un buen proyecto a nivel de centro que permita adquirir y desarrollar las competencias básicas necesarias para la vida adulta de nuestro alumnado.

\section{Referencias}

Alfageme, B., Miralles, P. y Monteagudo, J. (2015). Cómo evalúa el profesorado de Geografía e Historia de Enseñanza Secundaria. Revista Complutense de Educación, 26(3), 571-589. https://doi. org/10.5209/rev_RCED.2015.v26.n3.44428

Bernando, J. (1995). Cómo aprender mejor: estrategias de aprendizaje. Rialp.

Casas, M. (2004). Algunas reflexiones sobre la formación para la ciudadanía democrática. Pensar en el futuro partiendo del presente. En Ma.I. Vera-Muñoz y D. Pérez y Pérez (Coords)., Formación de la ciudadanía: Las TICs y los nuevos horizontes (pp. 407-422). Asociación Universitaria de Profesores de Didáctica de las Ciencias Sociales.

De Bono, E. (1988). Seis sombreros para pensar. Granica.

García, F. y De Alba, N. (2008, 26-30 de mayo). ¿Puede la escuela del siglo XXI educar a los ciudadanos y ciudadanas del siglo XXI?. Scripta Nova. Revista Electrónica de Geografía y Ciencias Sociales XII, 270(122). http://www.ub.edu/geocrit/-xcol/394.htm

González, M. C. y Tourón, J. (1992). Autoconcepto y rendimiento académico. Sus implicaciones en la motivación y en la autorregulación del aprendizaje. Eunsa.

Hernández, F. X. (2002): Didáctica de las ciencias sociales, geografía e historia. Editorial Graó.

Herrandis, B. (2003). Desarrollo de una metodología sistémica para el diseño de productos industriales. Tesis doctoral no publicada. Universidad Politécnica de Valencia. 
Merchán, F. J. (2007). El papel de los alumnos en la clase de historia como agentes de la práctica de la enseñanza. Didáctica de las Ciencias Experimentales y Sociales, 21, 33-51.

Miralles, P., Gómez, C. J. y Monteagudo, J. (2012). La evaluación de la competencia social y ciudadana en ciencias sociales al finalizar las etapas de primaria y secundaria. Investigación en la escuela, 78, 19-30. http://dx.doi.org/10.12795/E.2012.i78.02

Molina, J., Miralles, P. y Trigueros, F. J. (2014). La evaluación en ciencias sociales, geografía e historia: Percepción del alumnado tras la aplicación de la escala EPEGEHI-1. Educación XX1, 17(2), 289-311. https://doi.org/10.5944/educxx1.17.2.11492

Monteagudo, J. y Villa, J. L. (2011). La evaluación de las competencias básicas en la materia de Historia en $4{ }^{\circ}{ }^{\circ}$ de ESO en la Región de Murcia. En Miralles et al. (eds.), La evaluación en el proceso de enseñanza y aprendizaje de las ciencias sociales (pp. 317-325). Asociación Universitaria de Profesorado de Didáctica de las Ciencias Sociales.

Monteagudo, J., Miralles, P., Molina, S., Belmonte, P. (2010). La evaluación de contenidos procedimentales de Historia en $4 .^{\circ}$ de Educación Secundaria Obligatoria. Análisis crítico de programaciones de aula. En López Facal y Velasco-Martínez (eds.), I Congreso Internacional sobre enseñanza de la historia. Universidad de Santiago de Compostela.

Ortuño, J., Gómez, C. J. y Ortiz, E. (2012). La evaluación de la competencia educativa social y ciudadana desde la didáctica de las ciencias sociales. Un estado de la cuestión. Didáctica de las Ciencias Experimentales y Sociales, 26, 53-72. https://doi.org/10.7203/DCES.26.1931

Prats, J. y Santacana, J. (2011). ¿Por qué y para qué enseñar historia?. En AAVV: Enseñanza y aprendizaje de la Historia en la Educación Básica (pp. 18-68). Secretaría de Educación Pública.

Ruiz, J. M. (2002). Educación para el desarrollo: una apuesta globalizadora para el currículum de ciencias sociales (ESO). En Benejam, (coord.): Las ciencias sociales: conceptos y procedimientos (pp. 107-116). Graó.

Sanmartí, N. (2007). 10 ideas claves. Evaluar para aprender. Graó.

Tenbrink, T. (1981). Evaluación: guía práctica para profesores. Narcea.

Vallés, A. (1998). Estrategias de aprendizaje. Promolibro.

Zaragoza, J. M. (2004). Actitudes del profesorado de secundaria obligatoria hacia la evaluación de los aprendizajes de los alumnos. [Tesis Doctoral, Universidad Autónoma de Barcelona]. Repositorio TDX. http://hdl.handle.net/10803/5023 